\title{
Risk of Attritionfrom Master of Science in Pharmacy Degree Program: 15-year Predictive Evaluation
}

\author{
Mariusz Panczyk*, Henryk Rebandel, Jaroslawa Belowska, Aleksander Zarzeka and Joanna Gotlib \\ Division of Teaching and Outcomes of Education, Faculty of Health Sciences, Medical University of Warsaw, Poland.
}

\begin{abstract}
Aim: Evaluation of the selected socio-demographic factors and admission criteria for the MA pharmaceutical studies on the risk of attrition during studies at the Faculty of Pharmacy at the Medical University of Warsaw (MUW). Materials and Methods:1598 students who undertook studies of pharmacy between the years 20002009; observation of a full education cycle between October $1^{\text {st }} 2000$ and March $31^{\text {st }} 2015$. A model of logistic regression was used to evaluate predictive factors that are of potential influence on the risk of the delayed graduation or attrition. Results: For the model with the outcome variable "timely/delayed graduation" it was found that men bear nearly twice as big a risk of a delayed graduation than women $(O R=1.978 ; P=0.004)$. It was also observed that students recruited within a new system of admission have almost 10 times greater chances for a delayed graduation as opposed students from the years recruited on the basis of old regulations $(O R=10.224$; $\mathrm{P}<0.001)$. Moreover, for a regression model based on the outcome variable" timely graduation/attrition", it was also noted that men bear a greater risk of attrition than women $(\mathrm{OR}=3.621 ; \mathrm{P}<0.001)$ and that students recruited within a new system as opposed to the old one ( $O R=23.734 ; P<0.001)$. Also, good predictive ability was found for both recruitment criteria when evaluating the risk of attrition (OR for biology and chemistry was 0.974 and 0.958 , respectively). Additionally, it was observed the risk of attrition and failure to complete studies was age on entry $(O R=1.154 ; P=0.05)$. Conclusion: The obtained results of the predictive analysis allow determining a profile of a student who bears a high risk of attrition during studies at the pharmacy department: man who began his studies at least one after completing secondary school and achieved a score in chemistry and biology below the average compared to other candidates accepted to this faculty.
\end{abstract}

Key words: Pharmacy education, Retention, Student dropouts, Attrition, Educational status, Regression analysis.

\section{INTRODUCTION}

Every year academic centres educating pharmacists and chemists - to be face the necessity to select the best candidates wishing to undertake studies at this difficult and demanding faculty. Universities engage personnel and funds in order to perform a reliable admission process. This task becomes more and more difficult, especially in the recent years when a higher interest in this field among candidates is noted. This trend is observed worldwide, in the United States, ${ }^{1,2}$ Near East countries, ${ }^{3,4}$ Asia $^{5}$ and in Western Europe, ${ }^{6,7}$ but also in Poland. ${ }^{8}$ Selection of candidates becomes a very important element in a good admission strategy, especially in the times of a shortage of pharmacists and chemists on the labour market. This strategy may be directed at the increase of a number of accepted candidates so as to compensate the shortages, which also increases the risk of attrition among the people who undertook this type of studies. The above conditioning result in many academic centres seeking methods that would ensure maintaining a high percentage of success among the students.

Attrition during studies is normally connected with a career path change as well as professional plans of a students, and disappointing results in their education. High risk of attrition contributes to considerable financial losses. When it comes to educating pharmacists, there is no accessible data in this area, however, it is estimated that, e.g. at the faculty of Nurs-
Submission Date : 14-07-2015 Revision Date : :22-06-2015 AcceptedDate :19-07-2015

DOI: 10.5530/ijper.50.1.10 Correspondence Address Mariusz Panczyk, Pharm.D Division of Teaching and Outcomes of Education, Faculty of Health Science, Medical University of Warsaw, Zwirki iWigury 61, 02-091 Warsaw, Poland. Telephone: +48-225720490s

E-mail:mariusz.panczyk@ wum.edu.pl

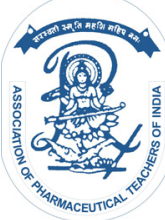

www.ijper.org 
ing, annual losses in Great Britain reach as much as 57 million pounds. ${ }^{9}{ }^{10}$ Apart from considerable financial losses, attrition also influences the increased time engagement of the academic personnel, which does not translate into the increased quality of teaching. The activities of the lecturers are dispersed on all students learning at a given faculty, both those who become successful and will eventually complete their studies, and those who will be crossed out from the students' list. It is of essence here to determine the reasons why their studies were interrupted, since students who make a conscious decision about resigning from studies (holidays, change of course/university) should be treated differently to those who are crossed out from the list of students because of insufficient learning progress. This information is particularly important for the academic circles because inappropriate construction of curriculum, ${ }^{11}$ lack of efficient strategy of supporting sudents in their academic adaptation, particularly in the first year of studies and not adjusting classes to educational needs, particularly when teaching clinical subjects ${ }^{12}$ are listed as factors influencing the percentage of students who did not complete their studies. Considering the above, it needs to be emphasised that the reasons of attrition lie not always on a student, but also on an academic institution. ${ }^{13}$

Carrying out research that would identify the factors influencing the risk of attrition during studies is aimed at establishing a "profile" of a student who is particularly threatened with timely completion of studies or bears a high risk of resignation during the course of studies. If we are able to identify students from the "risk group", then it will become possible to undertake such supporting actions that can effectively lower the risk of attrition.

One of the important aspects of research into the quality of admission policy is assessment of predictive ability of the selected forms of entry examinations. This analysis includes assessment of to what extent pre-pharmacy characteristics allow to accurately predict educational achievements of a student. Another significant area of research is determining which criteria of selection are best when predicting the future of graduates. As Ferguson et al. ${ }^{14}$ emphasise, it is necessary to carry outwell-planned, reliable and long-term research that would be aimed at establishing the actual predictive value of the selected cognitive and non-cognitive factors when predicting the future of students/graduates.

\section{AIM OF STUDY}

The results of retrospective research presented in this work concern evaluation of impact of the selected socio-demographic criteria and the criteria of admission to MA pharmaceutical studies on the risk of attrition during studies illustrated by data obtained at the Faculty of Pharmacy at the Medical University of Warsaw (MUW).

\section{MATERIALS AND METHODS}

\section{Description of the admissions selection process}

The Faculty of Pharmacy at MUW is one of the ten academic units at Polish medical universities that educate pharmacists at uniform MA studies. ${ }^{15}$ Annually, there are about 130 graduates of MUW who obtain the title of Master of Sciences of Pharmacy (MsPharm), which is about $10 \%$ of all students who graduate from this faculty in the whole of Poland. Until the academic year of 2004/05, there has been a uniform mechanism of selection of candidates in Poland, based on the results on the national aptitude test, the structure of which was similar to other exams of this kind, e.g. American Pharmacy College Admission Test (PCAT). ${ }^{16}$

A candidate could apply for a place at only one academic centre of their choice. The test, prepared by The Central Committee for Medical Examination, allowed to evaluate a candidate considering their knowledge and skills at secondary school level in two subjects: biology and chemistry. The test was performed at the same time throughout the whole country and included 120 closed multiple-choice questions (MCQs) (60 in each subject) in the format of the best answer from a list of possible answers. The test on entry and the computer calculation of the score based on uniform regulations provided this system with an advantage of objectivity.

Within the educational reform in Poland, since the academic year of 2005/06, there have been new regulations concerning admitting candidates to universities introduced, based on the results of the national maturity exam (the equivalent of A-levels in the UK, Baccalaureate in France, Maturità in Italyor Abitur in Germany). The result of this exam obtained by a candidate becomes the basis on which they may apply for the possibility of studying at every academic centre in Poland, including one of the ten centres educating in pharmacy. Additionally, candidates may apply for any number of faculties they choose, at universities of different profiles. Each university has the right to establish their own criteria that will be considered during the admission process, thus deciding which subjects and what level of advancement (elementary or extended) will become the basis of selection. Most medical universities that educate future pharmacists requires of a candidate to present the results of their maturity exam on an extended level in biology 
and chemistry. ${ }^{17}$ The maturity exam, prepared under the supervision of The Central Examination Board (CEB), consists of 30 or 40 open questions that evaluate knowledge and skills of reasoning, concluding, making use of information coming from various sources, description and analysis of phenomena and biological and chemical processes. External examiners evaluate the maturity exams in individual subjects and the score (there are maximum 100 points to be scored per each subject) is revealed to universities through The National Registry of Baccalaureate. ${ }^{18}$

\section{Data Collection}

There were 1598 students who qualified for the Pharmacy Department and who undertook their MA studies at MUW between the years 2000 and 2009. The observation included the full cycle of education of each year, beginning with October $1^{\text {st }} 2000$ until March $31^{\text {st }} 2015$. In the studied group, $3 / 4$ of the students were women and people who began their studies immediately after completing their secondary school were predominant. Attrition rate among the students was $10 \%$ and in a vast majority concerned the $1^{\text {st }}$ year students. Delayed graduation was similar. Data concerning variables such as gender, age on entry, place of completing the secondary school were obtained on the basis of information provided in application forms completed by candidates. As for the status of graduation, data were collected through The Central Database of Students which supports the administrative assistance of students and a given year of studies. There is a detailed characteristic of a given group in Table 1.

\section{Statistical analysis}

To analyse predictive factors that potentially may influence the risk of delayed graduation or attrition, a model of non-linear estimation was used for the function of logistic regression. In the suggested logistic model, four predictors were used which belonged to the group of socio-demographic factors: (1) gender, (2) age on entry, (3) place of completing the secondary school, and (4) type of admission system (old or new). Additionally, the model included two criteria variables used during the admission process for the university - score in biology and chemistry. The results of preliminary exams tests from the years 2000-2004 were obtained from the MUW Admission Board database. Whereas data from the years 2005-2009 were collected from the National Registry of Baccalaureate. As a dichotomous outcome variable, depending on the tested model, timely/delayed graduation (a variable coded as 0 and 1, respectively), or timely graduation/attrition (coded as 0 and 1, respectively) were used. Quasi-Newton method of estimation with determining asymptotic standard errors was used. For each predictor, odds ratio (OR) was established together with a $95 \%$ confidence interval so as to determine the risk of delayed graduation or attrition. In order to evaluate significant interactions between quality variables from the socio-demographic group with a variable of status of graduation, a log-linear model was used designed for the analysis of multi-dimensional contingency arrays. Calculations were performed in a statistical set of STATISTICA 12.5 (StatSoft ${ }^{\circ}$, Inc.) according to the MUW licence. For all analyses, the relevance level assumed a priori was $\alpha=0.05$.

\section{RESULTS}

Both of the tested models of logistic regression were statistically significant. For the model with the outcome variable "timely/delayed graduation" (loss of generality $\left.=346.721 ; \mathrm{chi}^{2}=32.552, \mathrm{P}<0.00001\right)$ it was found that men bear nearly twice as high a risk of delayed graduation than women $\left(\mathrm{OR}=1.978\right.$; Wald $\mathrm{Chi}^{2}$ test $=8.361$; $\mathrm{P}=0.004)$. It was also observed that students recruited within the new system have almost 10-times greater chances for delayed graduations opposed to students from the years recruited on the basis on old regulations $\left(\mathrm{OR}=10.224\right.$; Wald $\mathrm{Chi}^{2}$ test $\left.=22.395 ; \mathrm{P}<0.001\right)$. Moreover, between two recruitment criteria, it was discovered that only in case of the score in biology it has a significant influence on the risk of delayed graduation. An almost 37\% higher risk of attrition is noted in students who obtained a low score in biology during the admission process as opposed to those who had a high score in this subject $\left(\mathrm{OR}=0.963\right.$; Wald $\mathrm{Chi}^{2}$ test $=8.003$; $\mathrm{P}=0.005)$. A detailed summary of the results for the model of logistic regression with the outcome variable "timely/delayed graduation" is presented in Table 2.

The other of the tested models of regression was based on the outcome variable "timely graduation/attrition" (loss of generality $=323.952 ; \mathrm{chi}^{2}=69.308, \mathrm{P}<0.00001$ ). Similarly as with the first model, also in this case men bear a higher risk of attrition than women $(\mathrm{OR}=3.621$; Wald $\mathrm{Chi}^{2}$ test $\left.=30.629 ; \mathrm{P}<0.001\right)$ and students recruited within the new system as opposed to the old one $\left(\mathrm{OR}=23.734\right.$; Wald $\mathrm{Chi}^{2}$ test=37.232; $\left.\mathrm{P}<0.001\right)$. Also, for both admission criteria, good predictive ability was discovered when evaluating the risk of attrition. For score in biology it was 95\% and for chemistry 18\% higher chances of attrition in students with a low score during the admission process as opposed to those with a high score in those subjects (OR was 0.974 and 0.958 , respectively). Moreover, it was observed that the risk 
Table 1: Characteristic of a studied group of students who undertook MA studies at the pharmacy department at the Medical University of Warsaw between the years 2000-2009

\begin{tabular}{|c|c|}
\hline Total number of students & 1598 \\
Female & 1256 \\
Male & 342 \\
\hline Average age of students \pm SD & $19.1 \pm 1.22$ \\
\hline Number of student sin admission system & \\
for 2000-2004 (old system) & 813 \\
for 2005-2009 (new system) & 785 \\
\hline Place of completing the secondary school & 483 \\
Warsaw & 1115 \\
\hline other & 1246 \\
\hline Status of graduation & 164 \\
timely & 188 \\
\hline delayed & \\
\hline
\end{tabular}

SD - standard deviation

Table 2: Parameters model of logistic regression with an outcome variable: timely/delayed graduation (a variable coded as 0 and 1, respectively)

\begin{tabular}{|c|c|c|c|c|c|}
\hline \multirow{2}{*}{ Predictor } & \multirow{2}{*}{ OR } & \multicolumn{2}{|c|}{$95 \% \mathrm{Cl}$} & \multirow{2}{*}{ SE } & \multirow{2}{*}{$P$-value** } \\
\hline & & Lower & Upper & & \\
\hline Intercept of regression model & 0.539 & 0.026 & 11.033 & 1.538 & 0.688 \\
\hline Age on entry & 1.013 & 0.871 & 1.178 & 0.077 & 0.870 \\
\hline $\begin{array}{c}\text { Gender }^{*} \\
(0=\text { Female } ; 1=\text { Male })\end{array}$ & 1.978 & 1.245 & 3.141 & 0.236 & 0.004 \\
\hline $\begin{array}{l}\text { Place of completing the secondary school* } \\
\qquad(0=\text { Other; } 1=\text { Warsaw })\end{array}$ & 0.739 & 0.470 & 1.162 & 0.231 & 0.189 \\
\hline $\begin{array}{l}\text { Admission system* } \\
(0=\text { Old; } 1=\text { New })\end{array}$ & 10.224 & 3.899 & 26.807 & 0.491 & $<0.001$ \\
\hline Score of Biology & 0.963 & 0.939 & 0.989 & 0.013 & 0.005 \\
\hline Score of Chemistry & 0.987 & 0.964 & 1.010 & 0.012 & 0.263 \\
\hline
\end{tabular}

* binary variable(dichotomous variable)

** Wald statistic

OR - odds ratio

$95 \% \mathrm{Cl}-95 \%$ confidence interval for odds ratio

SE - standard error

\begin{tabular}{|c|c|c|c|c|c|}
\hline \multirow{2}{*}{ Predictor } & \multirow{2}{*}{ OR } & \multicolumn{2}{|c|}{$95 \% \mathrm{Cl}$} & \multirow{2}{*}{ SE } & \multirow{2}{*}{$P$-value ** } \\
\hline & & Lower & Upper & & \\
\hline Intercept of regression model & 0.056 & 0.003 & 1.028 & 1.480 & 0.052 \\
\hline Age on entry & 1.154 & 1.000 & 1.332 & 0.073 & 0.050 \\
\hline $\begin{array}{c}\text { Gender }^{*} \\
(0=\text { Female } ; 1=\text { Male })\end{array}$ & 3.621 & 2.294 & 5.714 & 0.232 & $<0.001$ \\
\hline $\begin{array}{l}\text { Place of completing secondary school* } \\
\qquad(0=\text { Other; } 1 \text { = Warsaw })\end{array}$ & 1.049 & 0.676 & 1.627 & 0.224 & 0.832 \\
\hline $\begin{array}{l}\text { Admission system* } \\
(0=\text { Old; } 1=\text { New })\end{array}$ & 23.734 & 8.572 & 65.717 & 0.519 & $<0.001$ \\
\hline Score in Biology & 0.974 & 0.949 & 1.000 & 0.013 & 0.047 \\
\hline Score in Chemistry & 0.958 & 0.936 & 0.981 & 0.012 & $<0.001$ \\
\hline $\begin{array}{l}\text { * binary variable(dichotomous variable) } \\
\text { ** Wald statistic } \\
\text { OR - odds ratio } \\
95 \% \mathrm{Cl}-95 \% \text { confidence interval for odds ratio } \\
\text { SE - standard error }\end{array}$ & & & & & \\
\hline
\end{tabular}




\begin{tabular}{|c|c|c|c|c|}
\hline \multirow{3}{*}{ Status of graduation } & \multirow{2}{*}{\multicolumn{2}{|c|}{ Gender }} & \multirow{2}{*}{\multicolumn{2}{|c|}{ Type ofadmission system }} \\
\hline & & & & \\
\hline & Female & Male & Old (2000-2004) & New (2005-2009) \\
\hline Timely graduation & $1022(81.4 \%)$ & $2240(65.5 \%)$ & $834(80.0 \%)$ & $412(74.1 \%)$ \\
\hline Delayed graduation & $113(9.0 \%)$ & $51(14.9 \%)$ & $99(9.5 \%)$ & $65(11.7 \%)$ \\
\hline Attrition & $121(9.6 \%)$ & $67(19.6 \%)$ & $109(10.5 \%)$ & $79(14.2 \%)$ \\
\hline
\end{tabular}

of attrition is also age on entry, although its negative influence was not significantly marked $(\mathrm{OR}=1.154$; Wald $\mathrm{Chi}^{2}$ test $=3.839 ; \mathrm{P}=0.05$ ). A detailed summary of the results for the model of logistic regression with the outcome variable "timely graduation/attrition" is presented in Table 3.

The best adjusted log-linear model was created on the basis of qualitative variables that included three secondary and tertiary interactions (Table 4). On the basis of this model it was found that there is a considerable dependency between the status of graduation and gender, and the type of admission system (secondary effects). Also, it was noted that the type of admission system and the place of completing secondary school interact with the status of graduation (tertiary effect). Whereas as irrelevant to the undertaken considerations, yet included in the model, was also the effect comprising of the variable gender and the place of completing secondary school.

\section{DISCUSSION}

There have been numerous works published in the recent years, describing the results of predictive analyses concerning the effectiveness of the admission process relating to students' learning outcomes obtained during the course of studies. These findings concerned both educating doctors, ${ }^{14}$ dentists ${ }^{19}$ or nurses ${ }^{20}$ but also pharmacists. ${ }^{16,17}$ To a much lesser degree there are also available results of analyses concerning the factors influencing attrition. In world literature, this issue is touched upon mainly when mentioning education of doctors ${ }^{21}$ and nurses. ${ }^{13}$ However, there is no long-term observation in this field in the context of educating pharmacists and chemists, which is the reason why the results presented here are of innovative character. Due to the fact that there is no relevant evidence in the area of conditions influencing attrition among students of pharmacy, it is necessary to base the findings on research performed for other medical professions.
In 1975, Vincent Tinto suggested a theory concerning conditions that have impact on attrition during studies. ${ }^{22}$ Tinto's theory assumes that the main reason of this phenomenon is inaccurate course of "academic integration" and "social integration". According to the above theory, a much less role should be attributed to such factors as: the student's personal attributes (socio-demographic background, entry qualifications, psychological attributes, etc.) and certain environmental forces (family, economy, other). However, empirical research carried out in later years gave grounds to the revision of the assumptions that even Tinto himself criticised to a certain degree. ${ }^{23,24}$ Currently, predictive research is focused mainly on the analysis of the above mentioned socio-demographic and environmental factors, and student's individual predispositions, paying much less attention to the issue of social integration.

One of the important predictors of attrition in the group of socio-demographic factors, is a student's gender. The results of self studies show that both in case of not timely completion of studies and not completing them at all, it is men who bear a greater risk of attrition than women (OR 1.978 and 3.621, respectively). Moreover, the suggested log-linear model for quality variables shows a significant interaction between the statusof graduation and a student's gender. The above observations are in compliance with the findings of other authors in the field of inter-gender differences in the achieved learning outcomes. ${ }^{17,25,26}$ The factors which can condition this state of a matter is a different level of motivation and different mechanisms of dealing with difficulties in learning that may be observed in women and men. For instance, Carroll et al., ${ }^{25}$ while studying students of pharmacy for applying different strategies of learning, noticed considerable inter-gender differences. Males most frequently reported use of recall ability, followed by general organization and planning and then environmental restructuring; whereas females reported greater reliance on general organizing and planning followed by recall ability and environmental restructuring. ${ }^{25}$ Two other studies report that female students use self- 
regulated learning strategies more frequently than male counterparts. ${ }^{27,28} \mathrm{By}$ and large, the majority of researchers claim that it is women who deal with studies better than men. ${ }^{26}$ Moreover, in the field of medical education, it was also observed that women, as opposed to men, have greater chances of obtaining a diploma with a distinction..$^{29} \mathrm{As}$ is concluded by Ferguson et al. ${ }^{14}$ on the basis of systematic literature review, it is recommended to consider gender as one of the important variables in predictive studies at medical faculties..$^{14} \mathrm{As}$ far as attrition is concerned, Arulampalam et al., ${ }^{30}$ in their studies carried out in the UK, found that men bear a greater risk of attrition than women $(\mathrm{OR}=1.19)$, although in their later works, the authors achieved contradictory results $(\mathrm{OR}=0.81) \cdot{ }^{31} \mathrm{Also}$, in case of a highly feminised profession such as nursing, it was observed that men bear a significantly higher risk of dropping out than women. ${ }^{13,32-34}$ On the other hand, studies performed among the participants of a military medical programme show that it is women who present a greater attrition risk than men $(\mathrm{OR}=2.4)$. Also, when learning at a dental school, a tendency is observed among men to achieve higher scores in the practical tests and better grade averages, however, there is no data on the subject of risk evaluation in this field of studies. ${ }^{35}$ Finally, many authors who undertake the subject of dropping out of medical studies showed no inter-gender differences in this area. ${ }^{36,37} \mathrm{An}$ in-depth analysis concerning inter-gender differences in the achieved learning outcomes suggests that they may be conditioned by a greater conscientiousness, more diligent work during exercises, more diligent attendance in women than men. ${ }^{38}$ However, in the context of a potential influence of gender in the students of pharmacy, further studies are necessary which would provide evidence supporting the thesis that this demographic variable is important when predicting attrition.

A candidate's age may also be of potential influence during studies (variable age on entry). However, the results of self studies show no significant role of a student's age on not timely completion of studies, and in case of being crossed out of the list of students, the negative influence of this variable was marked rather weakly ( $O R=1.154)$. As can be seen from the results of several predictive studies concerning educating health professionals (e.g. nurses), variable age is positively correlated with the results achieved during studies. ${ }^{13,32-34,39-42}$ Generally, in case of older students, significantly better results of learning are noted as opposed to students who began their studies under the age of 26, regardless of any additional qualifications on entry. ${ }^{32,40}$ In the studies on the reasons of attrition at the nursing department, it was the young age that was pointed to as a negative predictor. ${ }^{13,34,42}$ As is reported by Pryjmachuk et al., ${ }^{13}$ age on entry is of moderate influence when it comes to timely completion of studies at the nursing department. On the other hand, Arulampalam et al., ${ }^{30}$ in their studies carried out in the UK, showed that students of medicine who are older than 21 , bear a significantly higher risk of dropping out that younger students $(\mathrm{OR}=1.46)$, although these findings were not confirmed in their later studies. ${ }^{31}$ The impact of age on attrition at medicine was also a subject of analyses of two studies performed in the United States ${ }^{43,44}$ and one in Australia. ${ }^{45}$ The results of these studies give no coherent confirmation that a student's age is of significant predictive importance when predicting adverse learning outcomes. ${ }^{37} \mathrm{As}$ with gender, also evaluation of the influence of age on entry on the risk of attrition during studies at the pharmacy department, requires further analysis.

One of the studied variable from the group of economic/ environmental factors, was the place of completing secondary school education. This variable related to the fact whether a student undertaking education at university, received his/her secondary school education in the same city as the university. The results of the logistic regression analysis for the result variable timely/delayed graduation or for timely graduation/ attrition, show no significant influence of this predictor while evaluating the risk of attrition during studies at the pharmacy department. However, it was observed that the place of completing secondary school interacts with the status of graduation with a modifying influence of the type of admission system. This tertiary effect, noted in the log-linear model, proves there are certain possible dependencies between the place of completing secondary school and the risk of attrition during studies. As was mentioned before, in the analysis of regression it was not noted that students from outside Warsaw bore a lower risk of attrition as opposed to the "local" students. This observation may come as a surprise as it could have been assumed that in a group of "foreign" students there would be people whose choice of university was a well thought-through decision due to the necessity of organising their stay away from home. Thus, this group should be characterised by a greater motivation, determination and engagement in the process of learning. On the other hand, in case of "local" students, an increased risk of attrition could be expected due to the influence of economic factors, the increased cost of studying, away from home. Moreover, "foreign" students may have greater problems with adaptation and social integration, particularly in case of people who came to Warsaw from small towns and 
villages. An unambiguous conclusion of the influence of this variable on the course of studies requires additional studies that would expand the catalogue of the analysed criteria from the group of economic and environmental factors.

One of the key elements of a proper selection of candidates is a reliable and validity evaluation of a candidate's predispositions when it comes to studying at a given faculty. If we wish to perform a good selection of candidates, we follow the principle that we choose those who meet a certain minimum requirement concerning the range of knowledge and skills, and show certain predispositions that are needed in a given profession. Using tools of educational measurement that are inadequate in evaluating these features that are relevant in order to effectively undertake studies, contributes to a significant percentage of dropouts. As can be seen from the predictive analysis for the system of variables timely/ delayed graduation and timely graduation/attrition, a considerably higher risk of attrition was noted in a group of students recruited according to new regulations as opposed to those applied prior to the reform of the maturity exam (OR 10.224 and 23.734, respectively). Also the tested log-linear model for quality variables points to a significant effect of interaction between the status of graduation and the type of admission system. The above findings confirm that the new system of recruitment, based on the results of a national maturity exam, is characterised by a much worse predictive validity in relation to the system of candidates' selection basing on the national entry test exam. The reason for this may be found in a different specifics of both systems of admission. The pool of maturity test exam questions is prepared at the Central Examination Board by secondary school teachers and is not assessed with regards to the specific needs of competence measurement of university candidates. Maturity exams are directed primarily at measuring students' achievements in a given subject onthe secondary level. An exam of this kind is of a verifying character as it measures the level of obtained knowledge and skills in relation to the curriculum requirements for a given subject. An entry exam is of totally different character; its key role should be selecting the best candidates considering their predispositions and an appropriate level of competences on entry. Meanwhile, the same results of a maturity exam in biology and chemistry are used in parallel during recruitment at the medical analytics, dentistry and medicine faculties, and also at universities, at biological and chemical departments. National entry test exam used since 2005 was prepared by an academic team which included specialists coming directly from academic circles of medical universities. A special test, designed for a particular direction and evaluating a candidate's predispositions individually was prepared annually, depending whether the admission process concerned medicine or pharmacy. Thus, the old system shows many similarities to the American PCAT exam. Such a system of recruiting ensures good validity of selection, which is confirmed by the results of the regression analysis presented in this work.

As has already been indicated above, the task of an entry exam is not to verify the achieved learning outcomes at secondary school level, but to evaluate whether a candidate has the necessary competences on entry which are needed to undertake studies at the pharmacy department. Specificity of a given tool of evaluation is its ability to select candidates who should not be accepted (negative selection). From the point of view of selecting the best candidates, such criteria are more beneficial which are characterised by a significant specificity so as to avoid a situation in which there would be people representing insufficient level of competences on entry among those beginning their studies. Predictive analysis when evaluating the risk of not timely completion of studies shows that only the score in biology may be accepted as an efficient predictor $(\mathrm{OR}=0.963)$. However, in case of evaluating predictor in the analysis concerning the risk of attrition, it was shown that both admission criteria - biology and chemistry - are significant factors of risk evaluation (OR 0.974 and 0.958 , respectively). These results, which are in compliance with expectations, prove a significant specificity of the accepted admission criteria. This means that in case of students who were placed in the lower level of score, the risk of attrition was indeed much higher than in case of students with a higher score.

In the world literature, the influence of entry qualifications on the risk of failure was the subject of studies in the area of educating both doctors ${ }^{37}$ and nurses. ${ }^{13}$ As reported by O'Neill et al. ${ }^{37}$ in their literature review, generally, when educating doctors, it is observed that students with a low level of preparation for studies bear a greater risk of attrition. Similar observations were described by Pryjmachuk et al. ${ }^{13}$ in relation to educating nurses. However, it needs to be remembered that the problem of evaluating entry qualifications in predictive studies is complex due to the considerable differences concerning the evaluated competences, not only between the different professions, but also within a given direction of studies. The following are included in the catalogue of the evaluated qualifications: prior university degrees to performance on admission or aptitude tests, 
performance at summer school, formal pre-university academic / non-academic qualifications and even extracurricular achievement. Such a big differentiation in individual studies makes it impossible to compare and draw clear conclusions concerning the role of this variable when evaluating the risk of attrition during studies. It is an indisputable fact, however, that the admission system, and the accepted selection criteria in particular, do not play their role if a group of students is unable to meet the requirements due to the fact of lack of certain features and predispositions that were not been appropriately evaluated and verified during the admission to academic institutions.

\section{LIMITATIONS}

One of the main limitations of retrospective studies is lack of possibility to expand the data base by additional variables. This limitation is of particular importance in predictive studies. In majority of cases it is not possible or it is too costly to reach participants of the study and complete the data base with additional data. The analyses that are carried out are thus limited to only these variables that can be catalogued on the basis of accessible academic data. Another significant barrier that limits the possibility of generalise conclusions over a big population of students is the fact that the analysis of narrowed to one geographical a cultural area. That is why, the findings presented in this work ought to be treated with a certain reserve, including the local conditionings and a different specificity of education of pharmacists and chemists in different regions of the world.

\section{CONCLUSION}

The obtained results of a predictive analysis allow to create a model profile of a students who bears a high risk of attrition at the faculty of pharmacy: a male who began his studies at least one year after graduating from a secondary school and achieved score below average in his maturity exam in biology and chemistry as opposed to other candidates accepted at this direction of studies. The possibility of identifying a group of people for whom there is a greater chance of not timely completion of studies or being crossed out of the list of students, allows to implement a support programme. Comprehensive causal models of dropout that include educational, organisational and institutional influences need to be tested if we are to learn more about what might be done to prevent pharmacy student withdrawal. Moreover, it is recommended to collect and analyse data concerning the future of graduates of a pharmacy department further, so as to evaluate the impact of individual socio-demographic, economic and environmental factors on professional success achieved by pharmacists and chemists.

\section{CONFLICTS OF INTEREST}

The authors declare that they have no competing interests.

\section{SUMMARY}

- The profile of a students who bears a high risk of attrition: a male who began his studies at least one year after graduating from a secondary school and achieved score below average in his maturity exam in biology and chemistry as opposed to other candidates accepted at this studies.

- The possibility of identifying a group of people for whom there is a greater chance of not timely completion of studies or being crossed out of the list of students, allows to implement a support programme.

- It is recommended to collect and analyse data concerning the future of graduates of a pharmacy department further, so as to evaluate the impact of individual socio-demographic, economic and environmental factors on professional success achieved by pharmacists and chemists.

\section{Pictorial Abstract}

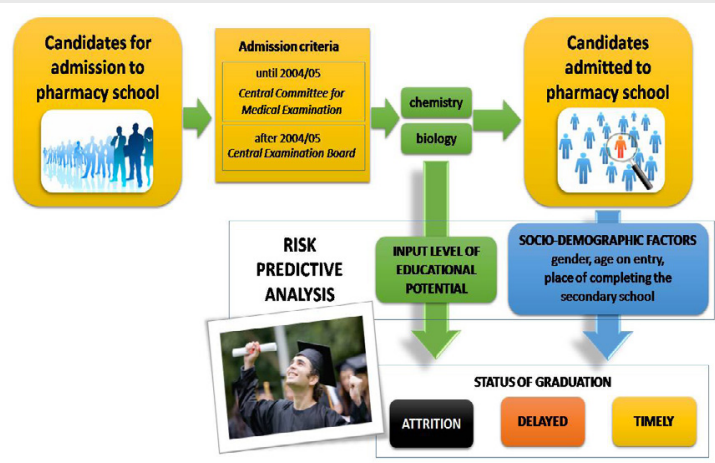




\section{About Authors}

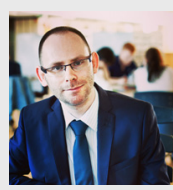

Mariusz Panczyk in 2003 he graduated from the Pharmaceutical Faculty, Medical University of Lodz and in 2007, at the same Faculty, he defended his PhD thesis on molecular biology and pharmacogenetics. Since 2008 he has been an assistant professor in the Division of Teaching and Outcomes of Education, Faculty of Health Science, Warsaw Medical University. In October 2013 she became Head of the Section of Evaluation and Improvement of Medical Education.

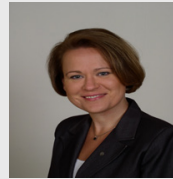
Joanna Gotlibin 2007 she graduated from Postgraduate Course in Medical Law, Bioethics and Sociology, Faculty of Law and Administration, Warsaw University. On March 12th, 2013, she defended her habilitation thesis composed of a series of studies entitled: "Development of occupational attitudes of physiotherapy students from different European and world countries" and became a Doctor Habilitatus of Health Sciences at the Faculty of Health Sciences. In October 2013 she became Head of the Division of Teaching and Outcomes of Education.

\section{ACKNOWLEDGEMENTS}

None.

\section{ABBREVIATION USED}

MUW: Medical University of Warsaw; MA: Master; MsPharm: Master of Sciences of Pharmacy; OR: odds ratio; PACT: American Pharmacy College Admission Test; MCQs: multiple-choice questions; CEB: The Central Examination Board; 95\%CI: 95\% confidence interval for odds ratio; SE: standard error; SD: standard deviation.

\section{REFERENCES}

1. Patton JM, Mayer AN, Meyer SM. The pharmacy student population: Applications received 2003-04, degrees conferred 2003-04, fall 2004 enrollments. Am J Pharm Educ. 2005; 69(1-5): S15.

2. Taylor DA, Patton JM. The pharmacy student population: applications received 2008-09, degrees conferred 2008-09, fall 2009 enrollments. Am J Pharm Educ. 2010; 74(10): S2.

3. Al-Wazaify M, Matowe L, Albsoul-Younes A, Al-Omran OA. Pharmacy education in Jordan, Saudi Arabia, and Kuwait. Am J Pharm Educ. 2006; 70(1): 18

4. Kheir N, Zaidan M, Younes H, El Hajj M, Wilbur K, Jewesson PJ. Pharmacy education and practice in 13 Middle Eastern countries. Am J Pharm Educ. 2008; 72(6): 133.

5. Basak SC, Sathyanarayana D. Pharmacy education in India. Am J Pharm Educ. 2010; 74(4): 68

6. Bourdon O, Ekeland C, Brion F. Pharmacy education in France. Am J Pharm Educ. 2008; 72(6): 132.

7. Sosabowski MH, Gard PR. Pharmacy education in the United Kingdom. Am J Pharm Educ. 2008; 72(6): 130.

8. Rebandel H. Region rekrutacji oraz wartość egzaminu testowego jako kryterium kwalifikacji na studia farmaceutyczne w Akademii Medycznej w Warszawie. Farm Pol. 2001; 57(23): 1071-7

9. Sabin M, Taylor R, Tilley C. Untangling a complex issue: An overview of initiatives to support nursing and midwifery student recruitment, selection and retention in Scottish Universities. Nurse Educ Today. 2012; 32(4): 469-74.

10. Gillen $\mathrm{S}$. Is enough being done to reduce undergraduate attrition rates? Nurs Stand. 2012; 27(8): 12-3.

11. White J, Williams WR, Green BF. Discontinuation, leaving reasons and course evaluation comments of students on the common foundation programme. Nurse Educ Today. 1999; 19(2): 142-50.

12. Cameron J, Roxburgh M, Taylor J, Lauder W. An integrative literature review of student retention in programmes of nursing and midwifery education: why do students stay? J Clin Nurs. 2011; 20(9-10): 1372-82.
13. Pryjmachuk S, Easton K, Littlewood A. Nurse education: factors associated with attrition. J Adv Nurs. 2009; 65(1): 149-60.

14. Ferguson E, James D, Madeley L. Factors associated with success in medical school: systematic review of the literature. BMJ. 2002; 324(7343): 952-7.

15. Bartkowiak LE. Professional views of pharmacy faculty graduates. Wiad lek. 2006; 59(5-6): 303-10

16. Kuncel NR, Crede M, Thomas LL, Klieger DM, Seiler SN, Woo SE. A metaanalysis of the validity of the Pharmacy College Admission Test (PCAT) and grade predictors of pharmacy student performance. Am J Pharm Educ. 2005; 69(3): 339-47.

17. Panczyk M, Rebandel H, Gotlib J. Assessment of predictive value of admission criteria of candidates for pharmaceutical studies - an empirical investigation. Indian J Pharm Educ Res. 2015; 49(2): 112-20.

18. The Central Examination Board: http://www.cke.edu.pl/(access 14-07-2015)

19. Buyse T, Lievens F, Martens L. Admission systems to dental school in Europe: a closer look at Flanders. Eur J Dent Educ. 2010; 14(4): 215-20.

20. Schmidt B, MacWilliams B. Admission criteria for undergraduate nursing programs: a systematic review. Nurse Educ. 2011; 36(4): 171-4.

21. O'Neill LD, Wallstedt B, Eika B, Hartvigsen J. Factors associated with dropout in medical education: a literature review. Med Educ. 2011; 45(5): 440-54.

22. Tinto V. Dropout from higher education: A theoretical synthesis of recent research. Rev Educ Res. 1975; 45(1): 89-125.

23. Tinto V. Leaving college: Rethinking the causes and cures of student attrition, $2^{\text {nd }}$ Edition. University of Chicago Press. Chicago; 1993.

24. Metz GW. Challenge and changes to Tinto's persistence theory: A historical review. J Coll Stud Ret. 2004; 6(2): 191-207.

25. Carroll CA, Garavalia LS. Gender and racial differences in select determinants of student success. Am J Pharm Educ. 2002; 66(4): 382-7.

26. Pai MRSM, Sanji N, Pai PG, Kotian S. Comparative assessment in pharmacology multiple choice questions versus essay with focus on gender differences. J Clin Diagn Res. 2010; 4(3): 2515-20.

27. Ablard KE, Lipschultz RE. Self-regulated learning in high-achieving students Relations to advanced reasoning, achievement goals, and gender. J Educ Psychol. 1998; 90(1): 94-101.

28. Zimmerman BJ, Martinez-Pons M. Student differences in self-regulated learning: Relating grade, sex, and giftedness to self-efficacy and strategy use. J Educ Psychol. 1990; 82(1): 51-9.

29. McDonough CM, Horgan A, Codd MB, Casey PR. Gender differences in the results of the final medical examination at University College Dublin. Med Educ. 2000; 34(1): 30-34.

30. Arulampalam W, Naylor R, Smith J. Factors affecting the probability of first year medical student dropout in the UK: a logistic analysis for the intake cohorts of 1980-92. Med Educ. 2004; 38(5): 492-503.

31. Arulampalam W, Naylor RA, Smith JP. Dropping out of medical school in the UK: explaining the changes over ten years. Med Educ. 2007; 41(4): 385-94.

32. McCarey M, Barr T, Rattray J. Predictors of academic performance in a cohort of pre-registration nursing students. Nurse Educ Today. 2007; 27(4): 357-64 
33. Mulholland J, Anionwu EN, Atkins R, Tappern M, Franks PJ. Diversity, attrition and transition into nursing. J Adv Nurs. 2008; 64(1): 49-59.

34. Kevern J, Ricketts C, Webb C. Pre-registration diploma students: a quantitative study of entry characteristics and course outcomes. J Adv Nurs. 1999; 30(4): 785-95.

35. Beier US, Kapferer I, Ostermann H, Staudinger R, Dumfahrt H. Impact of a novel dental school admission test on student performance at Innsbruck Medical University, Austria. J Dent Educ. 2010; 74(5): 531-8.

36. Cohen-Schotanus J, Muijtjens AM, Reinders JJ, Agsteribbe J, van Rossum HJ, van der Vleuten CP. The predictive validity of grade point average scores in a partial lottery medical school admission system. Med Educ. 2006; 40(10): 1012-9.

37. O'Neill L, Hartvigsen J, Wallstedt B, Korsholm L, Eika B. Medical school dropout - testing at admission versus selection by highest grades as predictors. Med Educ. 2011; 45(11): 1111-20.

38. Zwick R, Greif Green J. New Perspectives on the Correlation of SAT Scores, Secondary school Grades, and Socioeconomic Factors. J Educ Meas. 2007; 44(1): 23-45.
39. Madigan V. Predicting prehospital care students' first-year academic performance. Prehosp Emerg Care. 2006;10(1):81-8

40. Ofori R. Age and 'type' of domain specific entry qualifications as predictors of student nurses' performance in biological, social and behavioural sciences in nursing assessments. Nurse Educ Today. 2000; 20(4): 298-310.

41. Van Rooyen P, Dixon A, Dixon G, Wells C. Entry criteria as predictor of performance in an undergraduate nursing degree programme. Nurse Educ Today. 2006; 26(7): 593-600.

42. Houltram B. Entry age, entry mode and academic performance on a Project 2000 common foundation programme. J Adv Nurs. 1996; 23(6): 1089-97.

43. Hojat M, Gonnella JS, Erdmann JB, Veloski JJ. The fate of medical students with different levels of knowledge: Are the basic medical sciences relevant to physician competence? Adv Health Sci Educ Theory Pract. 1996; 1(3): 179-96.

44. Stetto JE, Gackstetter GD, Cruess DF, Hooper TI. Variables associated with attrition from Uniformed Services University of the Health Sciences Medical School. Mil Med. 2004; 169(2): 102-7.

45. Neame RL, Powis DA, Bristow T. Should medical students be selected only from recent school-leavers who have studied science? Med Educ. 1992; 26(6): 433-40. 